\title{
The Influence of Gender on the Teachers' Degree of Organizational Commitment in Arab Schools in Israel
}

\author{
Fathi Mohsen Shamma* \\ Ministry of Education -Israel \\ *Corresponding author: fsh1308@gmail.com
}

\begin{abstract}
The current study aimed to identify the impact of gender on the degree of the organizational commitment among the Arab schools' teachers in Israel. The study sample consisted of (250) male and female teachers in the Arab schools in Israel; to achieve the objectives of the study, the researcher used the analytical, descriptive approach where he prepared a questionnaire as a tool for data collection from the members of the study sample. After conducting the appropriate statistical methods, the researcher in this study concluded the following results: there is a very great degree in the level of the organizational commitment among the teachers in the Arab schools in Israel, there are no statistically significant differences at the level of significance $(\mathrm{a}=0.05)$ for the degree of the level of the organizational commitment among the teachers in the Arab schools in Israel from their perspective according to the impact of gender, According to the results, the study recommended the need to maintain and strengthen this degree through continuing and preserving this status and conducting studies on the organizational commitment and its relationship to other demographic variables, such as the educational level, the educational stage, and the type of school.
\end{abstract}

Keywords: organizational commitment, gender, teachers in the Arab schools in Israel

Cite This Article: Fathi Mohsen Shamma, "The Influence of Gender on the Teachers' Degree of Organizational Commitment in Arab Schools in Israel." American Journal of Educational Research, vol. 6, no. 4 (2018): 349-353. doi: 10.12691/education-6-4-8.

\section{Introduction}

Organizational commitment is one of the most important indicators of human behavior that is characterized by complexity, which includes all processes as well as intellectual, motor, emotional and social activities, where individuals do to compliment and adapt the environment he lives in, satisfy his needs, and solve his problems.

Researchers have concentrated their effort in management science on the human resource by studying its behavior and trying to influence this behavior as it is the main element that helps organizations to achieve the desired goals. Many variables may affect the individual and his performance positively or negatively in the organization, where the organizational commitment is considered as one of those variables that received great attention by both researchers and administrators. Moreover, organizational commitment is one of the most desirable behaviors in all organizations that are always sought to strengthen it in the individuals working in it [1]. Organizational commitment represents the strong and emotional feeling of the organization in which the employee works through his absolute belief in the goals and values of the organization, and the constant desire to make all possible efforts to preserve it [2].

The school is considered as one of the most important educational organizations that aim at educating human beings and helping them to develop and expand all aspects of their personality (mental, physical, psychological, spiritual and social), according to their ability, readiness, tendencies and trends, with this growth directed at the right social destination. In order for the school to function properly, physical and human resources are needed [3]. The teacher is needed who plays an important role in the students' lives by preparing them and providing them with the knowledge, skills and attitudes that will then become eligible for future life [4]. The teacher, by his status, plays important and renewed roles, where he plans to teach, implements and guides the process of learning and interaction among students, and opens the horizons for their collaborative and innovative work [5]. Therefore, it requires the best choice of the teacher and follow-up, development, to appear at its best, empowering him and his integrity, honesty and commitment [6].

\section{Theoretical framework}

\subsection{Organizational Commitment Concept}

Organizational commitment is defined as an important part of the employee's psychological condition. Individuals with a high level of commitment usually exhibit positive behaviors in the workplace, such as job satisfaction and organizational citizenship, which is of great benefit to the organization ([7]: p3). Joo and Shim [8] also defined organizational commitment as an individual's belonging and active attachment to the organization's 
goals and values, regardless of the material value achieved by the organization.

Kean et al., [9] conducted a study aimed at determining the relationship between the administrative practices of principals and the organizational commitment of teachers. The researchers used the descriptive expressive method. The study sample consisted of (340) secondary school teachers in Malaysia. The study found that there is a high degree of commitment among teachers in everything related to teaching and that there is a strong relationship between the practices of the principal and the commitment of teachers with regard to improving working conditions, including the educational climate and giving opportunities to participate in decision-making.

Mousa and Ruth [10] conducted a study to determine the degree of organizational commitment of teachers in primary schools in Menoufia Governorate in Egypt. The study sample consisted of (150) teachers where descriptive statistical method was used. The results of the study showed that teachers are committed to their work for the success of their schools despite some differences in working conditions (involving teachers in decisionmaking and equal opportunities).

Srinivansan and Selvi [11] conducted a study to determine the degree of commitment of secondary school teachers in India. The study sample consisted of (300) male and female teachers. The sample was randomly selected from (100) schools. The researchers followed the descriptive expressive method. The study revealed that there is a high degree of organizational commitment among teachers regardless of gender. The researchers noted that teachers in city schools have a higher degree of commitment than teachers in rural schools, as well as for public school teachers compared to private schools.

In addition, Cogaltay [12] conducted a meta-analysis, summarizing the impact of gender on Turkish teachers on their perception of organizational commitment. The metaanalysis included (30) studies conducted throughout Turkey where (11724) teachers participated. The results showed that organizational commitment is not affected by gender.

\subsection{Dimensions of Organizational Commitment}

Many researchers have sought to determine the dimensions of organizational commitment and to determine the nature of the change in the organizational and behavioral variables. These scientists have shown that there are three dimensions of organizational commitment and they are as follows [13]:

First: emotional commitment (effect) which means the degree of the effect of the distinctive characteristics of work on the individual that includes the degree of independence and diversity of the required skills. It also include the supervisors closeness and guide of the individual, it is also affected by the degree to which the employee feels empowered to participate effectively in decision-making in the organizational environment in which he or she works, whether in relation to his work or that of the employee himself, as well as the feedback he receives from supervision.

Second: The normative obligation (moral) which means the feeling of the employee towards the commitment and stay in the organization. This supports the organization's support for its employees, allowing the organization to participate actively and positively in setting goals, planning and shaping the organization's public policies, contributing to the development of procedures and implementation of work, and carrying out the normative commitment where employees believe that staying in the organization is a moral and a correct thing to do.

Thirdly: Continuous commitment which means what the employees achieve of investment value if they continue to work in the organization in exchange for what they will lose when joining other parties, and that employees who have a high level of continuous commitment remain in service because they are in need and not desire.

\subsection{Significant of the Study}

The importance of this study is highlighted by the fact that it deals with an administrative issue of the most important topics, which is the organizational commitment. This topic has witnessed a lot of interest in the last period due to its psychological impact on the performance of teachers in schools. The results of this study may be important in the following points:

1. Scarcity of studies that dealt with the subject of organizational commitment, especially those that tried to study the effect of demographic variables (gender) on the organizational commitment of teachers in Arab schools in Israel, which makes this study a scientific addition to the theoretical literature.

2. The importance of the desired results of this study and related recommendations in helping officials to identify the reasons that prevent the availability of organizational climate in their organizations and how to face them as well as modifying the behavior of their employees.

\subsection{Study Objectives}

This study aimed at identifying:

1. The level of organizational commitment of schoolteachers in Arab schools in Israel from their point of view.

2. If there is a statistically significant differences at the level of significance $(\alpha=0.05)$ in the respondents' responses to the level of organizational commitment of Arab school teachers in Israel from their point of view due to the gender variable.

\section{Method and Procedures}

Study Methodology: The descriptive expressive approach that fits the nature of the current study and its objectives was used.

Population: The study population consists of all male and female teachers in Arab schools in Israel, numbering (4500) male and female teachers, during the academic year 2017-2018.

Sample: The study sample consisted of (250) male and female teachers from the study population, numbering 
(4500) in the Arab schools in Israel in their three stages (elementary, preparatory and secondary), i.e 5.5\% of the study population. On the study sample, (300) questionnaires were distributed, where excluded (50) questionnaires were excluded, the sample of the study consisted of (250) valid questionnaire for analysis. Table (1) shows the distribution of the sample members according to the study variables (gender, scientific qualification, experience and educational level).

Table 1. Distribution of the sample of the study according to the gender variable

\begin{tabular}{|c|c|c|c|}
\hline Variable & Level / category & Number & Percentage \% \\
\hline \multirow{2}{*}{ Gender } & Male & 105 & 42.0 \\
\cline { 2 - 4 } & female & 145 & 58.0 \\
\hline \multicolumn{2}{|c|}{ Total } & 250 & 100.0 \\
\hline
\end{tabular}

The above table shows that the female number was the higher with a percentage of $58.0 \%$, while the males were $42.0 \%$ from the study sample. The analysis showed also that the categories of years of experience variable for the $11-20$ years were the highest with a percentage of (40.0\%), followed by a category of more than 21 years with a percentage of (34.0\%).

\subsection{Study Variables}

The study included the following variables:

1. Independent variables

A. A gender with two categories: (male and female)

2. The dependent variable
B. Organizational commitment of the teachers in (elementary, preparatory and secondary) stages in Arab schools in Israel.

\section{Results and Discussion}

The answer to the first question of the study, which states: What is the level of organizational commitment of teachers in Arab schools in Israel from their point of view?

In order to answer this question, the mean, standard deviations and ranks were extracted from the study sample responses on the level of organizational commitment of schoolteachers in the Arab schools in Israel from their point of view, as follows:

This field includes (18) paragraphs, to identify the level of organizational commitment of the teachers in Arab schools in Israel. The sample members see that the level of organizational commitment was very high, and the total mean was (4.32), the means and standard deviations have been extracted for each paragraph of the field.

The table shows that the values of the means for this field ranged between (3.79-4.72), which is generally very high. Paragraph (4), which states (The reputation of the school concerns me) ranked first with a mean of (4.72) and a standard deviation of (.57), followed by the second paragraph, which states (Always attend school). With a mean of (4.58) and a standard deviation of (666), The paragraph (5) that states "If I has the chance to work in the school after retire I will agree" was ranked last with a mean of (3.79) and a standard deviation of (1.282), which reflects the very high level of distributive justice.

Table 2. The means and standard deviations of the areas of the organizational commitment filed arranged in descending order by the means

\begin{tabular}{|c|c|c|c|c|c|}
\hline No & Rank & Paragraphs & Mean & Standard deviation & Level \\
\hline 4 & 1 & The reputation of the school concerns me & 4.72 & .572 & Very high \\
\hline 6 & 2 & Always attend school. & 4.58 & .666 & Very high \\
\hline 18 & 3 & Management relationship is built on mutual respect & 4.46 & .786 & Very high \\
\hline 7 & 4 & I prefer the public interest over the personal interest. & 4.41 & .756 & Very high \\
\hline 8 & 5 & I am proud to be attending this school & 4.41 & .792 & Very high \\
\hline 14 & 6 & I am ready to keep up with the latest developments to achieve the school's objectives. & 4.41 & .722 & Very high \\
\hline 10 & 7 & I make a great effort to help the school to achieve its goals & 4.40 & .724 & Very high \\
\hline 12 & 8 & I am ready to do any task that gave to me in the school & 4.40 & .712 & Very high \\
\hline 1 & 9 & I encourage parents to register their children in the school & 4.38 & .802 & Very high \\
\hline 2 & 10 & I will participate in the school activities & 4.38 & .755 & Very high \\
\hline 13 & 11 & My school is an organization that is good to work in & 4.38 & .817 & Very high \\
\hline 16 & 12 & I invest my time effectively. & 4.33 & .723 & Very high \\
\hline 9 & 13 & I am following up the administrative and organizational affairs of the school & 4.27 & .834 & Very high \\
\hline 3 & 14 & The school motivates me to provide the best performance. & 4.23 & .848 & Very high \\
\hline 17 & 15 & I have the willing to stay at my school until I retire & 4.22 & .975 & Very high \\
\hline 11 & 16 & I have the willing to work in the school outside the working hours & 4.02 & .975 & High \\
\hline 15 & 17 & The justice organizational climate in the school makes teachers committed to their goals & 3.99 & 1.000 & High \\
\hline 5 & 18 & If I has the chance to work in the school after retire I will agree & 3.79 & 1.282 & High \\
\hline & & Organizational Commitment & 4.32 & .581 & High \\
\hline
\end{tabular}


This result is attributed to the teachers' belief in the decisions and actions taken in a fair and transparent manner. Thus, the employees succeed in performing the tasks entrusted to them in an effective and worthy manner. The male and female teachers also believe in the goals of their organization, and working hard to achieve the goals and vision. The previous result is existed in paragraph (10) that states, "I make a great effort to help the school to achieve its goals" with a mean of (4.40). Paragraph (16), which states (I invest my time effectively) has a mean of (4.33), the principals' awareness of the importance of the partnership, which creates a high spirit and morale among the teachers, and then increases the commitment and belonging of the teacher will increases his efforts regardless of the financial value achieved by the organization, [14].

Through the results, it was noted that teachers are aware of the importance of maintaining their work as a source of livelihood; teachers are subjected to evaluation annually where the possibility of getting faire is existed. In the globalization context, the competition between schools has increased. One of the criteria that measure the quality of the school is the educational climate where the teachers are the most important part of it through their hard work to achieve the goals of the school and follow all the developments and innovations to give them to their students. This requires a degree of commitment. The fact that each renewal is introduced to the school requires additional work and training and rehabilitation courses.

This can be seen in paragraphs (14) that states, "I am ready to keep up with the latest developments to achieve the school's objectives" with a mean of (4.41), and paragraph (11) that states, "I have the willing to work in the school outside the working hours" with a mean of (4.02). In addition, paragraph (12) that states, "I am ready to do any task that gave to me in the school" had the same idea with a mean of (4.40).

The researcher believes that the relationship between principals and teachers is based on mutual respect, which is clearly reflected in the high degree of commitment of teachers [15]. This is stated in paragraph (18) that states, "Management relationship is built on mutual respect" with a mean of (4.46). Building social relationships between teachers and management strengthens cohesion, understanding, enhances the spirit of teamwork, reduces negative competition among teachers and highlights efforts among individuals in the interest of the organization and its objectives. This can be seen in paragraph (7) that states, "I prefer the public interest over the personal interest" with a mean of (4.42).

The principals realization of what is related to organizational justice and their work to achieve it is a protective wall in front of the latest developments because teachers are the cornerstone in reaching the desired goals. Achieving justice provides the principal with teachers committed to their responsibility and works to achieve the school vision, this is reflected in paragraph (15) that states, "The justice organizational climate in the school makes teachers committed to their goals" with a mean of (3.99).

Paragraph (3) that states, "The school motivates me to provide the best performance" came with a mean of (4.23).
This is due to the high efficiency of teachers, in addition to the internal control, self-commitment and maintenance of the job, as well as by the prevailing positive educational teaching, the procedures of transparent policy and their fairly implementation, regardless of the demographic variables.

This stands out in both paragraph (1) that states, "I encourage parents to register their children in the school" with a mean of (4.38) and paragraph (4) that states, " The reputation of the school concerns me" with a mean of (4.72) a high degree of organizational commitment that is due to the job security.

This is attributed to the clear policy in the Ministry of Education that the funding of the school and the granting of the hours of the owners are in accordance with the number of students in the school and the reputation of the school, which encourage parents to register their children in the school guarantees the teacher continuity in work or increase in the proportion of the job or promotion.

It was noted that teachers are working intensively and seriously to ensure the superiority of their school in the educational and social fields to gain the confidence of the people on one hand and to win the respect of the principal on the other.

While paragraph (5), which states "If I has the chance to work in the school after retire I will agree" came in the last rank with a mean of (3.79), this result explains that teachers are aware that they cannot work after retirement, it also needs special approval and it is rarely granted.

The result of the study in this question was consistent with the studies of Kean et al., [9], Ari et al. [16], Mousa \& Ruth [10], Srinivansan \& Selvi [11].

The answer to the second question, which states, Are there statistically significant differences at the level of significance $(\alpha=0.05)$ in the respondents' responses to the level of organizational commitment of Arab school teachers in Israel from their point of view due to the gender variable?

In order to answer this question, the means and standard deviations of the responses of the sample members to the level of organizational commitment of Arab school teachers in Israel were derived from their point of view due to the gender variable in Table 3 .

Table 3. The means and the standard deviations of respondents' responses to the level of organizational commitment of teachers of Arab schools in Israel from their point of view is due to gender variable

\begin{tabular}{|c|c|c|c|}
\hline Variable & Level & mean & standard deviation \\
\hline \multirow{2}{*}{ Gender } & Male & 4.32 & .596 \\
\cline { 2 - 4 } & Female & 4.32 & .569 \\
\hline
\end{tabular}

Table 3 shows the variance of the mean and the standard deviations of the level of organizational commitment of Arab school teachers in Israel from their point of view according to the gender variable due to the different categories of the study variables. To illustrate the significance of the statistical differences between the means, the binary variance analysis was used as in Table 4: 
Table 4. Binary variance analysis of the of the effect of the study variables on the level of organizational commitment of teachers of Arab schools in Israel from their point of view according to the gender variables

\begin{tabular}{|c|c|c|c|c|c|}
\hline Field & $\begin{array}{c}\text { Squares } \\
\text { sum }\end{array}$ & $\begin{array}{c}\text { Freedom } \\
\text { degrees }\end{array}$ & $\begin{array}{c}\text { Squares } \\
\text { mean }\end{array}$ & $\begin{array}{c}\mathbf{P} \\
\text { Value }\end{array}$ & $\begin{array}{c}\text { Statistical } \\
\text { Significance }\end{array}$ \\
\hline Gender & .147 & 1 & .147 & .478 & .490 \\
\hline Error & 68.251 & 221 & .309 & & \\
\hline
\end{tabular}

* Statistical significance at the level of statistical significance $(\alpha=0.05)$.

Table 4 shows that there are no statistically significant differences at the level of significance $(\alpha=0.05)$ attributed to the degree of organizational commitment of teachers of Arab schools in Israel from their point of view due to the impact of the gender variable.

This result is attributed to the researcher's view that the absence of statistically significant differences in the impact of gender variable indicates a high level of organizational justice, which is reflected in several aspects, the principle of gender equality, and that schools apply laws and practices without discrimination between male and female teachers. Male and female teachers have a high degree of belonging to the school and can be attributed to the social and professional environment in which the study was conducted. This contributes to the reduction of many conflicts among organization members and the increase in the sense of commitment to work because the policy is clear and fair. Moreover, faith in the organization allows for effective participation in decision-making and procedures that determine the fate of the school and the transparency principle in what is related to the work or the individual personality of male and female teachers, although there is different evidence about the effects of demographic variables on organizational commitment.

\section{Conclusions}

- The results showed a very high degree of organizational commitment among teachers of Arab schools in Israel.

- There are no statistically significant differences at the level of significance $(\alpha=0.05)$ to the level of organizational commitment among teachers of Arab schools in Israel from their point of view due to the gender variable

\section{Recommendations}

- The results of the present study show the high degree of application of the organizational commitment of the teachers of Arab schools in Israel. In view of this result, the study recommends that this degree has to be maintained and strengthened through the continuation and preservation of this status.
- Conduct studies on the organizational commitment and its relation to other demographic variables such as the level of education, years of experience and educational stage in Arab schools in Israel.

\section{References}

[1] Alkhishrum, M. M. (2011). The Effect of the Service Climate on Organizational Commitment, A Field Study on Workers in Technological Institutes of the University of Halab. Damascus University, Journal of Economic and Legal Sciences, 27 (3), 169199.

[2] Kadiresan, V., Selamat, M., Selladurai, S., Ramendran, Ch., \& Mohamed, M. (2015). Performance appraisal and training and development of human resource management practices (HRM) on organizational commitment and turnover intention. Asian Social Science, 11(24), 162-176.

[3] Al-Rashidi, S. (2010). Personal Attitudes of High School Principals in Hail Educational Region and Their Relation to Administrative Creativity from Their Point of View. Unpublished Master Thesis, Mutah University, Karak, Jordan.

[4] Al-Lozi, K. M. (2012). Levels of Emotional Intelligence for Secondary School Principals and their Impact on Organizational Loyalty in Amman Governorate. Unpublished Master Thesis, Middle East University, Amman, Jordan.

[5] Hess, R. (2007). Follow the teacher: Making adifference for school improvement. Devon, MD: Rowman and Littlefield.

[6] Abu Al-Aini, J. (2002). The Origins of Management in the Quran and Sunnah. I. Beirut: Dar Al-Hilal Library.

[7] Albdour, A. \& Altarawneh, (2014). Employee Engagement and Organizational Commitment: Evidence from Jordan. International Journal of Business, 19(2), 192-212.

[8] Joo B. \& Shim, J. (2010). Psychological empowerment and organizational commitment: the moderating effect of organizational learning culture. Human Resource Development International, 13 (4), 425- 441.

[9] Kean, T. H., Kannan, S., Piaw, C. Y., (2017), The Effect of School Bureaucracy on the Relationship between Principals Leadership Practices and Teacher Commitment in Malaysia Secondary schools Malaysian Online Journal of Educational Sciences, 5(1), 37-55

[10] Mousa, M., \& Alas, R. (2016). Cultural diversity and organizational commitment: A study on teachers of primary public schools in Menoufia (Egypt). International business research. 9(7), 154-163.

[11] Srinivasan, P., Selvi, K., (2016), Organizational Commitment of Higher Secondary School Teachers, American Journal of EducationalResearch, 4(5), 404-407.

[12] Cogalty, N., Organizational commitment of teachers: A metaanalysis study for the effect of gender and material status in Turkey, Journal Aim \&Scope, 15(4),911-924.

[13] Moloantoa, M. (2015). Factors affecting job satisfaction of academic employees: A case study of the National University of LESOTHO. Master thesis, University of technology, Durban, South Africa.

[14] Altahayneh, Z., Khasawneh, A., Abedalhafiz, A., (2014), Relationship between Organizational Justice and Job Satisfaction as Perceived by Jordanian Physical Education Teachers, Asian Social Science, 10(4), 131-138.

[15] Bidgoli, M., Saadati, A., Asghari, A., Saadati, M., Ghodsi, A., Bidgoli, A. (2015). Analyzing the relationship between the perception of Organizational Justice and Organizational Commitment. Case study: Neyshabur Medical Science Collage. International Journal of Academic Research in Accounting, Finance and Management Sciences. 5(3): 83-90.

[16] Ari, A., Caglayan, H. (2017). Relationship between organizational justice perceptions and organizational commitment levels of school of physical education and sports academicians. Journal of education and training studies. 5(4), 240-251. 